\title{
Perception of Premenstrual Syndrome and Attitude of Evaluations of Work Performance among Incoming University Female Students
}

\author{
Shu Hui Cheng ${ }^{1,2}$, Zih-Jie Sun ${ }^{3}$ I Hui Lee ${ }^{1,2,4}$, Chi-Chen Shih ${ }^{5}$, Kao Chin Chen ${ }^{2,4,6}$, Shih-Hsien Lin ${ }^{2,4}$, \\ Feng-Hwa Lu ${ }^{5}$, Yi-Ching Yang, ${ }^{5,7}$, Yen Kuang Yang ${ }^{2,4,7}$
}

Background: Premenstrual syndrome (PMS) is a common condition, and for $5 \%$ of women, the influence is so severe as to interfere with their mental health, interpersonal relationships, or studies. Severe PMS may result in decreased occupational productivity. The aim of this study was to investigate the influence of perception of PMS on evaluation of work performance.

Methods: $\quad$ A total of 1971 incoming female university students were recruited in September 2009. A simulated clinical scenario was used, with a test battery including measurement of psychological symptoms and the Chinese Premenstrual Symptom Questionnaire.

Results: When evaluating employee performance in the simulated scenario, $1565(79.4 \%)$ students neglected the impact of PMS, while 136 (6.9\%) students considered it. Multivariate logistic regression showed that perception of daily function impairment due to PMS and frequency of measuring body weight were significantly associated with consideration of the influence of PMS on evaluation of work performance.

Conclusion: It is important to increase the awareness of functional impairments related to severe PMS.

At a Glance Commentary

Scientific background of the subject

Helping the sick and disabled is the norm in our society, and thus it is very difficult to obtain honest and authentic answers using traditional methods when asking people to evaluate sick or disabled employees with a poor work performance. Factors contributing to behaviors of helping the sick and disabled could be important in medical education.

\section{What this study adds to the field}

We used a simulated clinical scenario for participants in order to detect their responses as a proxy of behavioral changes. Premenstrual syndrome was chosen due to its ambiguous impact on women from the perspective of the general public. The results showed that it is important to increase the awareness of functional impairments.

(Biomed J 2015;38:167-172)

Key words: functional impairment, premenstrual syndrome, simulated scenario, work evaluation

$\mathrm{P}$ remenstrual syndrome (PMS) is a common condition, and for $5 \%$ of women, the influence is so severe as to interfere with their personal relationships, studies, or work, with many cases requiring pharmacological treatment. ${ }^{[1]}$ PMS is thought to be clinically underdiagnosed. Women who received a diagnosis of PMS reported that prior to the
PMS diagnosis, they had sought medical help for a mean of 5.33 years from an average of 3.75 physicians. ${ }^{[2]}$ In Taiwan, the average latency from the onset of menopausal symptoms to seeking evaluation at clinics was $16.8 \pm 27.7$ months. ${ }^{[3]}$ In addition, there are still some members of the public who do not accept that severe PMS is a serious condition, and

From the ${ }^{1}$ Office of Student Affairs, National Cheng Kung University, Tainan, Taiwan; ${ }^{2}$ Department of Psychiatry, National Cheng Kung University Hospital, College of Medicine, National Cheng Kung University, Tainan, Taiwan; ${ }^{3}$ Department of Family Medicine, National Cheng Kung University Hospital, Dou-Liou Branch, Yunlin, Taiwan; ${ }^{4}$ Addiction Research Center, National Cheng Kung University, Tainan, Taiwan; ${ }^{5}$ Department of Family Medicine, National Cheng Kung University Hospital, College of Medicine,

National Cheng Kung University, Tainan, Taiwan; ${ }^{6}$ Department of Psychiatry, National Cheng Kung University Hospital, Dou-Liou Branch, Yunlin, Taiwan; ${ }^{7}$ Institute of Behavioral Medicine, College of Medicine, National Cheng Kung University, Tainan, Taiwan; ${ }^{8}$ Institute of Public Health, College of Medicine, National Cheng Kung University, Tainan, Taiwan

Received: Sep. 30, 2013; Accepted: Jun. 27, 2014

Correspondence to: Dr. Yi-Ching Yang, Department of Family Medicine, National Cheng Kung University Hospital. 138 Sheng Li Rd., North Dist, Tainan 704, Taiwan. Tel: 886-6-2754243; Fax: 886-6-2091433; E-mail: yiching@ mail.ncku.edu.tw

DOI: $10.4103 / 2319-4170.138319$ 
thus are unsympathetic toward affected women. ${ }^{[4]}$ There is also some debate as to whether PMS is associated with the performance of women in the workplace ${ }^{[5,6]}$ Although PMS is very common, Houston et al. ${ }^{[7]}$ indicated that only $2 \%$ of teenage women reported receiving information regarding menstruation from their healthcare providers. In some conservative areas, such as Asian countries, menstruation and its related problems are considered to be taboo topics. ${ }^{[8,9]}$ Additionally, it is also known that women with PMS report a poorer health-related quality of life, and that PMS may result in increased healthcare utilization and decreased occupational productivity. ${ }^{[10]}$

It is well known that there is a close relationship between changes in attitudes and perceptions and changes in behavior. ${ }^{[1]}$ However, evaluations of behavioral changes after a health education course are difficult to carry out in practice. A promising approach to assessing the outcomes of such an educational program is one in which researchers develop a simulated clinical scenario for participants in order detect their responses as a proxy of behavioral changes. ${ }^{[12-14]}$ Many researchers have shown that students' attitudes toward a disease or condition might be influenced by their personality, cultural background, lifestyle, health condition, perception, and health-related knowledge..$^{[15-17]} \mathrm{In}$ addition, whether or not the student suffers from that disease or condition is also an important factor that influences their attitude toward it. ${ }^{[18]}$

College can be a critical period with regard to developing a better understanding of certain physical conditions. ${ }^{[19]}$ The aim of this study was, therefore, to investigate the influence of incoming female university students' perception of PMS on their evaluation of work performance in a simulated scenario.

\section{METHODS}

\section{Participants}

A total of 5936 incoming students at National Cheng Kung University were enrolled in 2009, after they had been invited to participate in this self-administered questionnaire-based study during a routine health examination performed as part of the orientation procedure. Incoming students were new students at the university who were in their first few weeks, whether at the undergraduate or post-graduate level. Prior to the start of the study, informed consent was obtained from each participant. Specifically, the participants agreed to allow their questionnaire data and related examination results to be analyzed anonymously, and any identifying information was therefore kept confidential, with the Ethical Committee for Human Research at the National Cheng Kung University Hospital approving the study protocol. Because females may suf- fer from and know better about PMS, only 2115 female students were recruited in this study. In total, data from 1971 female students were used in final analysis.

\section{Assessment of personal lifestyle habits}

The demographic characteristics, personal medical history, and lifestyle habits of the participants were evaluated using a self-reported questionnaire. Body mass index (BMI) was calculated as weight in kilograms divided by the square of height in meters. Following the World Health Organization (WHO) standard BMI cutoffs, the participants were classified into underweight (BMI < 18.5), normal weight (BMI 18.5-24.9), overweight (BMI 25-29.9), and obese (BMI $\geq 30$ ) groups. Chronic physical disease was defined as the presence of at least one of the following diseases: Hypertension, diabetes, thyroid disease, coronary artery disease, cerebral vascular disease, and asthma. The personal lifestyle habits assessed included coffee or tea drinking, alcohol drinking, cigarette smoking, and regular exercise. Students were considered to drink coffee or tea regularly if they did so at least three times per week. In terms of alcohol drinking, students were classified as current drinkers if they drank alcohol at least once per week. Habitual smoking was defined as smoking at least 20 cigarettes per month for the last 6 months. The frequency of body weight measurement was defined as never, monthly, weekly, or daily.

\section{Measurement of psychological symptoms}

The instruments used to measure the psychological symptom domains included the 12 -item Chinese Health Questionnaire (CHQ-12), ${ }^{[20]}$ the Chinese Premenstrual Symptoms Questionnaire (PMSQ), and the Chinese version of the World Health Organization Quality of Life (WHOQOL) test. ${ }^{[21]}$

\section{The 12-item Chinese health questionnaire}

The CHQ-12 is a culturally sensitive tool for detecting potential psychiatric morbidity among Chinese individuals. It is a standardized self-reported screening instrument and has been previously used in surveys of minor psychiatric morbidity in three communities in Taiwan. ${ }^{[22]}$ It can be used to identify a "probable clinical case" on the basis of a cut-off score, and to determine the severity of morbidity on the basis of the total score, which ranges from zero to 12 , with higher scores indicating psychiatric morbidity of greater severity. The sensitivity and specificity of this tool in predicting cases of psychiatric morbidity were $69.6 \%$ and $98.4 \%$, respectively (in a community study with a cut-off between 2 and 3). ${ }^{[2]}$ In our study, a probable case of psychiatric morbidity was defined using a cut-off value between 3 and 4 and high psychiatric morbidity was defined as having a score of 4 or above on the CHQ-12. 


\section{World Health Organization Quality of Life}

Subjectively perceived health-related quality of life was assessed using the Chinese version of the WHOQOL brief version questionnaire. ${ }^{[21]}$ This 28 -item questionnaire has been demonstrated to be culturally relevant, with good reliability. Five sub-scores are obtained from this instrument, measuring overall (two items), physical (seven items), psychological (six items), social relations (four items), and environmental quality of life (nine items). The internal consistency of the questionnaire, as measured by Cronbach's $\alpha$, is satisfactory (0.82). Only the overall domain of the WHOQOL (two items) was applied in this study because in our previous work, this was found to be correlated with a biological marker, serotonin transporter availability. ${ }^{[23]}$

\section{The Chinese premenstrual symptoms questionnaire}

The PMSQ was revised from the DSM-IV-TR criteria A of PMS, which is a self-rated tool used to screen for premenstrual symptoms in the previous year. The PMSQ (Cronbach's $\alpha=0.76$ ) reflects and translates the DSM-IV-TR criteria into an 11-item symptom checklist, which comprises two categories: Primary symptoms (4 items) and other symptoms (7 items). ${ }^{[2]}$ Participants with PMS are defined as those with at least 5 of the 11 symptoms, including at least one primary symptom in category A according to the DSM-IV-TR criteria with premenstrual dysphoric disorder, and whose symptoms are noted 1 week before menstruation and disappear after menstruation has been completed. The participants who met these criteria were designated as the PMS group in this study and the others were designated as the non-PMS group.

\section{Simulated clinical scenario}

To investigate the factors associated with the perceived influence of illness on decision-making, a simulated clinical scenario test was developed to assess whether the respondents thought that decision-making is affected by PMS. The scenario was as follows.

"Suppose you are a manager leading five employees in a company. Each one of them has worked equally hard. Due to the economic crisis, you, the manager, have to lay off one of them. However, the employee who performed most poorly suffers from PMS. What would you do in this situation?"

Please choose one of the following possible decisions:

A. Even though they have all worked equally hard, the one with the poorest performance should be laid off for the sake of fairness

B. As everyone worked equally hard, it is difficult to decide. They should draw lots to decide who should be the one to be laid off
C. Because the employee who performed most poorly had PMS, the one with the second worst performance should be laid off

D. It is too difficult to make this decision. The manager should resign to avoid this dilemma.

Response C (laying off the employee with the second worst performance) indicates that the respondent's decision-making was altered by, and in favor of, the employee with PMS. Response A (laying off the one with the poorest performance due to PMS) indicates that the decision-making was not altered by, and thus not in favor of, the employee with PMS. Because responses B and D were considered ambivalent, these were deleted from the subsequent analysis. The reason why the respondents played the role of a manager in this scenario is that graduates from National Cheng Kung University are viewed more favorably by Taiwanese companies than those from any other universities in Taiwan. Therefore, we speculated that many of the surveyed students will become managers in the future.

Additionally, a four-item PMS perception-related questionnaire was also used to collect data. Item 1 was "perceived gender discrimination," item 2 was "estimated prevalence of women affected by PMS, and item 3 was "estimated daily function impairment due to PMS." A visual analog scale was used to assess these three items. Item 4 was "Do you think that female employees should tell their managers that they suffer from PMS?"

\section{Statistical methods}

Group differences between those making a decision in favor of the employee with PMS and those making the opposite decision were analyzed using the Chi-square test. Because there are more than 10 demographic characteristics in one study, in this serial analyses, we chose 0.005 as the level of significance, with the Bonferroni correction, and only the variables with a $p$ value lower than 0.005 , for the correction of multiple comparisons, were put into the multivariate logistic regression model, which was used to analyze the associations between the multiple risk factors and making a decision in favor of the employee with PMS. The odds ratio (OR) and 95\% confidence interval (CI) of each predictor were also derived. All the analyses were carried out using SPSS software (version 17; SPSS Inc., Chicago, IL, USA).

\section{RESULTS}

A total of 1971 incoming female university student participants completed the questionnaires and responded to the scenario (response rate $=1971 / 2115=93.2 \%$ ). Also, $1565(79.4 \%)$ students made a decision that was not in favor of the employee with PMS and 136 (6.9\%) made a 
decision that favored her. The other $270(13.7 \%)$ students chose response $\mathrm{B}$ or $\mathrm{D}$, and these were excluded from the subsequent analysis.

The characteristics of the two groups that made decisions in favor of and not in favor of the employee with PMS are shown in Table 1. The frequency of measuring body weight and the estimated daily function impairment due to PMS differed significantly between the two groups. The results of multivariate logistic regression analysis are presented in Table 2, and show that the frequency of measuring body weight and estimated daily function impairment due to PMS were significantly associated with making a decision in favor of the employee with PMS. More specifically, the female students who infrequently measured their own body weight and estimated more than $40 \%$ daily function impairment due to PMS were more likely to make a decision in favor of the employee with PMS.

\section{DISCUSSION}

Helping the sick and disabled is the norm in our society, and thus it is very difficult to obtain honest and authentic answers using traditional methods when asking people to evaluate sick or disabled employees with a poor work performance. In addition to the taboos around speaking honestly about such issues, there are also laws in Taiwan to protect disabled people at work. In this study, PMS was chosen due to its ambiguous impact on women from the perspective of the general public. Although PMS is a common condition and has been shown to decrease occupational productivity, ${ }^{[10]}$ the majority of women are reluctant to seek help or mention their PMS-related issues in public. ${ }^{[25,26]}$ This study examined the perceptions of incoming female university students with regard to their evaluation of the impact of PMS on work performance. Although various lifestyle and health condition variables were examined, the results showed that only the factors of less focus on body weight and a greater perception that PMS impairs functionality are likely to positively affect decisions in favor of employees with PMS.

Estimated daily functional impairment in work performance was found to be the most significant predictor of favoring the employee with PMS in the scenario examined in this work. Although functional assessment is important for medical conditions, physicians and health educational programs tend to pay more attention to the etiology of each condition at the biomedical or molecular level, as well as the outcomes based on their survival rates. In contrast, concerns about the related functional impairments are frequently neglected. It was found in this study that the greater the perception of the negative functional influence of PMS, the more likely that a person will carry out behaviors that favor people suffering from PMS. This supports a number of earlier studies which found that educating the public on
Table 1: Differences in demographic characteristics between those making a decision in favor of the employee with PMS versus those making the opposite decision

\begin{tabular}{lccccc}
\hline Predictors & $\begin{array}{c}\text { Not in } \\
\text { favor of the } \\
\text { employee }\end{array}$ & $\begin{array}{c}\text { In favor } \\
\text { of the } \\
\text { employee }\end{array}$ & & Statistics \\
& $\begin{array}{c}\text { with PMS } \\
\text { with PMS }\end{array}$ & & \\
\cline { 5 - 6 } & $1565(92.0)$ & $136(8.0)$ & $\chi^{2}$ & $p$ \\
\hline $\begin{array}{l}\text { Degree } \\
\text { Post-graduate }\end{array}$ & $837(53.5)$ & $59(43.4)$ & 5.12 & 0.024 \\
$\quad$ Undergraduate & $728(46.5)$ & $77(56.6)$ & & \\
Chronic physical diseases & & & & \\
$\quad \begin{array}{l}\text { Yes } \\
\text { No }\end{array}$ & $74(5.0)$ & $4(3.1)$ & 0.90 & 0.342 \\
& $1415(95.0)$ & $125(96.9)$ & &
\end{tabular}

Coffee drinking

(times per week)

$\begin{array}{lcccc}\geq 3 & 157(10.1) & 8(5.9) & 2.49 & 0.115 \\ <3 & 1404(89.9) & 128(94.1) & & \\ \text { Tea-drinking (times per week) } & & & & \\ \geq 3 & 594(38.1) & 38(28.1) & 5.29 & 0.021 \\ <3 & 964(61.9) & 97(71.9) & & \\ \text { Alcohol drinking } & & & & \\ \quad \text { Yes } & 19(1.2) & 2(1.5) & 0.06 & 0.800 \\ \text { No } & 1539(98.8) & 134(98.5) & & \end{array}$

Cigarette smoking

Yes

$5(0.3) \quad 1(0.7)$

$0.61 \quad 0.436$

No

$1539(99.7) \quad 134(99.3)$

Regular exercise

(times per week)

$<3$

$\geq 3$

$1288(83.6) \quad 111(82.8) \quad 0.06 \quad 0.810$

$252(16.4) \quad 23(17.2)$

BMI $\left(\mathrm{kg} / \mathrm{m}^{2}\right)$

$<18.5$

$324(20.7) \quad 39(28.7) \quad 5.23 \quad 0.156$

$18.5-24.9$

25-29.9

$\geq 30$

$1103(70.5) \quad 86(63.2)$

$99(6.3) \quad 9(6.6)$

$39(2.5) \quad 2(1.5)$

Frequency of body weight

measurement

Monthly or none

$612(39.4) \quad 73(53.7) \quad 10.69 * 0.0047$

Weekly

Daily

$606(39.0) \quad 39(28.7)$

$335(21.6) \quad 24(17.6)$

Quality of life in WHOQOL

Good

Bad

$634(40.8) \quad 47(34.6) \quad 2.22 \quad 0.330$

Neutral

$150(9.7) \quad 16(11.8)$

$769(49.5) \quad 73(53.7)$

Satisfaction with health in WHOQOL

$\begin{array}{lcccc}\text { Good } & 458(29.5) & 35(25.7) & 1.40 & 0.496 \\ \text { Bad } & 268(17.3) & 28(20.6) & & \\ \text { Neutral } & 824(53.2) & 73(53.7) & & \\ \text { CHQ-12 } & & & & \\ \geq 4 & 270(17.7) & 27(20.3) & 0.57 & 0.452 \\ <4 & 1256(82.3) & 106(79.7) & & \end{array}$

Perceived gender discrimination

\begin{tabular}{lllll} 
In favor of males & $917(58.7)$ & $80(58.8)$ & 0.86 & 0.652 \\
\hline
\end{tabular} Contd.. 
Table 1: Contd....

\begin{tabular}{|c|c|c|c|c|}
\hline \multirow[t]{2}{*}{ Predictors } & \multirow{2}{*}{$\begin{array}{c}\text { Not in } \\
\text { favor of the } \\
\text { employee } \\
\text { with PMS } \\
1565(92.0)\end{array}$} & \multirow{2}{*}{$\begin{array}{l}\text { In favor } \\
\text { of the } \\
\text { employee } \\
\text { with PMS } \\
136(8.0)\end{array}$} & \multicolumn{2}{|c|}{ Statistics } \\
\hline & & & $\chi^{2}$ & $p$ \\
\hline In favor of females & $107(6.9)$ & $12(8.8)$ & & \\
\hline Neutral & $538(34.4)$ & $44(32.4)$ & & \\
\hline \multicolumn{5}{|c|}{$\begin{array}{l}\text { Estimated prevalence affected } \\
\text { by PMS }(\%)\end{array}$} \\
\hline$>60$ & $545(34.9)$ & $47(34.8)$ & 0.00 & 1.000 \\
\hline$<40$ & $93(6.0)$ & $8(5.9)$ & & \\
\hline $40-60$ & $923(59.1)$ & $80(59.3)$ & & \\
\hline \multicolumn{5}{|c|}{$\begin{array}{l}\text { Estimated daily function } \\
\text { impairment due to PMS (\%) }\end{array}$} \\
\hline$>60$ & $592(37.9)$ & $68(50.0)$ & $11.82 *$ & 0.003 \\
\hline$<40$ & $434(27.8)$ & $21(15.4)$ & & \\
\hline $40-60$ & $535(34.3)$ & 47 (34.6) & & \\
\hline \multicolumn{5}{|c|}{$\begin{array}{l}\text { Discloses issue of suffering } \\
\text { from PMS }\end{array}$} \\
\hline Yes & $1144(75.2)$ & $100(74.6)$ & 1.33 & 0.513 \\
\hline No & $32(2.1)$ & $1(0.7)$ & & \\
\hline Other & $346(2.7)$ & $33(4.7)$ & & \\
\hline \multicolumn{5}{|l|}{ PMS } \\
\hline Yes & $642(41.6)$ & $49(36.3)$ & 1.46 & 0.227 \\
\hline No & $900(58.4)$ & $86(63.7)$ & & \\
\hline
\end{tabular}

Data are expressed as numbers (percentages). Chronic physical diseases include hypertension, diabetes, thyroid disease, coronary heart disease, cerebral vascular disease, and asthma. ${ }^{*} p<0.005$. Abbreviations: PMS: Premenstrual syndrome; BMI: Body mass index; WHOQOL: World health organization quality of life; CHQ-12: 12-item chinese health questionnaire

Table 2: Factors influencing making a decision in favor of the employee with PMS identified by multivariate logistic regression analysis, with only the significant variables shown

\begin{tabular}{lcccc}
\hline Predictors & OR & $95 \%$ CI & $p$ \\
\hline Frequency of measuring body weight & & & & 0.003 \\
$\quad$ Monthly or never vs. weekly & 1.94 & 1.29 & 2.91 & 0.001 \\
$\quad \begin{array}{l}\text { Daily vs. weekly } \\
\text { Estimated daily function impairment }\end{array}$ & 1.12 & 0.66 & 1.90 & 0.664 \\
$\quad \begin{array}{l}\text { due to PMS (\%) } \\
\quad>60 \text { vs. 40-60 }\end{array}$ & & & & 0.002 \\
$<40$ vs. 40-60 & 1.28 & 0.87 & 1.90 & 0.210 \\
\hline
\end{tabular}

-2 Log likelihood: 921.10; Cox and Snell $R^{2}$ : 0.01; Nagelkerke $R^{2}: 0.03$. Abbreviations: PMS: Premenstrual syndrome; OR: Odds ratio; CI: Confidence interval

the functional impact of various medical conditions may be helpful with regard to chronic diseases such as low vision or epilepsy. ${ }^{[27-29]}$

In the female students examined in this work, being less concerned about their own weight was a significant predictor of making a decision that favors the employee with PMS. Generally speaking, it is difficult to make decisions that go against social norms. Health is related to frequent monitoring of one's weight, and maintaining a healthy and attractive body is socially desirable. It is thus reasonable that female students who pay less attention to their weight may be less inclined to meet social expectations, and so make decisions based on factors other than the prevailing social norms. Surprisingly, the results did not show that the female students in general, who may all potentially suffer from PMS, were more likely to favor the employee suffering from PMS, as they were less concerned about the impact of PMS in the workplace. It thus appears that a greater awareness of a condition does not guarantee greater acceptance of it or more favorable responses to sufferers of it. Similarly, an earlier study found that Swiss mental health professionals did not have fewer negative stereotypes about mentally ill people than the general public, ${ }^{[30]}$ even though they were more familiar with such individuals, in line with the findings of this study.

The use of a standard questionnaire combined with a simulated scenario is becoming increasingly common, as this ensures a more objective, open, and fair process of evaluating health/mental promotion programs. The present study indicated that students' perceptions of PMS are related to their decision-making. Greater awareness of the influence of the functional impairments related to PMS is thus an important factor that should be considered in future for health/ mental promotion programs aimed at the general public.

This study has several limitations. First, we only identified the influential factors in this cross-sectional study, and therefore, no causal relationships can be confirmed. Second, we did not conduct individual interviews to confirm the diagnosis of PMS among students, and the severity of PMS was not analyzed. Third, because students are generally naive and sympathetic, their responses may tend to favor the employee with PMS. In addition, the definition of favoring the employee with PMS, based on the scenario presented in this work, could be confounded by social norms and the different phases of menstruation occurring among the participants when they complete the questionnaire, and therefore, caution should be taken while generalizing these findings. Fourth, only one question was used to assess the young female students' perceptions about PMS, and they may not really know what PMS and its related symptoms are, and this may underestimate the related results. More additional questions should be used to assess the respondents in the future. Fifth, the goodness of fit of model might not be good enough. Further studies are needed to find out more important factors. Finally, excluding the participants who did not complete the entire questionnaire might also have affected the findings.

\section{Acknowledgments}

The authors thank Professor Kow-Tong Chen and Professor Tsung-Hsueh Lu in the Department of Public Health, 
National Cheng Kung University, as well as the students of National Cheng Kung University who participated in this study. This study received no funding and the authors report no commercial interests related to this work.

\section{REFERENCES}

1. Dimmock PW, Wyatt KM, Jones PW, O'Brien PM. Efficacy of selective serotonin-reuptake inhibitors in premenstrual syndrome: A systematic review. Lancet 2000;356:1131-6.

2. Kraemer GR, Kraemer RR. Premenstrual syndrome: Diagnosis and treatment experiences. J Womens Health 1998;7:893-907.

3. Hsiao MC, Chiang PH, Liu CY, Lin YH. Help-seeking behavior in Taiwanese woman with menopause-related mood symptoms. Chang Gung Med J 2009;32:313-9.

4. Futterman LA, Rapkin AJ. Diagnosis of premenstrual disorders. J Reprod Med 2006;51 (Suppl 4):349-58.

5. Hardie EA. PMS in the workplace: Dispelling the myth of cyclic dysfunction. J Occup Organ Psychol 1997;70:97-102.

6. Bedeian AG, Phillips AS. PMS in the workplace: Myth or method? Soc Behav Pers 1998;26:357-62.

7. Houston AM, Abraham A, Huang Z, D'Angelo LJ. Knowledge, attitudes, and consequences of menstrual health in urban adolescent females. J Pediatr Adolesc Gynecol 2006;19:271-5.

8. Avasarala AK, Panchangam S. Dysmenorrhoea in different settings: Are the rural and urban adolescent girls perceiving and managing the dysmenorrhoea problem differently? Indian J Community Med 2008;33:246-9.

9. Wong LP. Attitudes toward menstruation, menstrual-related symptoms, and premenstrual syndrome among adolescent girls: A rural school-based survey. Women Health 2011;51:340-64.

10. Borenstein JE, Dean BB, Endicott J, Wong J, Brown C, Dickerson V, et al. Health and economic impact of the premenstrual syndrome. J Reprod Med 2003;48:515-24

11. Ajzen I, Fishbein M. Attitude-behavior relations: A theoretical analysis and review of empirical research. Psychol Bull 1977;84:888-918.

12. Tan GM, Ti LK, Suresh S, Ho BS, Lee TL. Teaching first-year medical students physiology: Does the human patient simulator allow for more effective teaching? Singapore Med J 2002;43:238-42.

13. King JM, Reising DL. Teaching advanced cardiac life support protocols: The effectiveness of static versus high-fidelity simulation. Nurse Educ 2011;36:62-5.

14. Wolf L, Dion K, Lamoureaux E, Kenny C, Curnin M, Hogan MA, et al. Using simulated clinical scenarios to evaluate student performance. Nurse Educ 2011;36:128-34.

15. Keskin G, Engin E, Dulgerler S. Eating attitude in the obese patients: The evaluation in terms of relational factors. J Psychiatr Ment Health
Nurs 2010;17:900-8

16. Al Robaee AA. Prevalence, knowledge, beliefs and psychosocial impact of acne in University students in Central Saudi Arabia. Saudi Med J 2005;26:1958-61.

17. Zhong X, Tanasugarn C, Fisher EB, Krudsood S, Nityasuddhi D. Awareness and practices of self-management and influence factors among individuals with type 2 diabetes in urban community settings in Anhui Province, China. Southeast Asian J Trop Med Public Health 2011;42:184-96.

18. Helle L, Nivala M, Kronqvist P, Ericsson KA, Lehtinen E. Do prior knowledge, personality and visual perceptual ability predict student performance in microscopic pathology? Med Educ 2010;44:621-9.

19. Oprendek TS, Malcarne VL. College student reasoning about illness and psychological concepts. J Am Coll Health 1997;46:10-9.

20. Chong MY, Wilkinson G. Validation of 30- and 12-item versions of the Chinese Health Questionnaire (CHQ) in patients admitted for general health screening. Psychol Med 1989;19:495-505.

21. Yao G, Chung CW, Yu CF, Wang JD. Development and verification of validity and reliability of the WHOQOL-BREF Taiwan version. J Formos Med Assoc 2002;101:342-51.

22. Cheng TA. A community study of minor psychiatry morbidity in Taiwan. Psychol Med 1988;18:953-68.

23. Tsai HC, Yeh TL, Hsieh MH, Lee IH, Chen KC, Chen PS, et al. Association between serotonin transporter availability and overall rating scores of quality of life in healthy volunteers. Prog Neuropsychopharmacol Biol Psychiatry 2009;33:711-4.

24. Cheng SH, Shih CC, Yang YK, Chen KT, Chang YH, Yang YC. Factors associated with premenstrual syndrome-A survey of new female university students. Kaohsiung J Med Sci 2013;29:100-5.

25. Johnson SR. The epidemiology and social impact of premenstrual symptoms. Clin Obstet Gynecol 1987;30:367-76.

26. Johnson SR. Premenstrual syndrome, premenstrual dysphoric disorder, and beyond: A clinical primer for practitioners. Obstet Gynecol 2004;104:845-59.

27. Newsham Beckley M, Teaford MH, Kegelmeyer D, Balaswamy S, Flom R, Raasch T. Interdisciplinary allied health education in treating older adults with low vision. J Allied Health 2007;36:e192-202.

28. Kim MK, Kim IK, Kim BC, Cho KH, Kim SJ, Moon JD. Positive trends of public attitudes toward epilepsy after public education campaign among rural korean residents. J Korean Med Sci $2003 ; 18: 248-54$

29. Green AE, Bekman NM, Miller EA, Perrott JA, Brown SA, Aarons GA. Parental awareness of substance use among youths in public service sectors. J Stud Alcohol Drugs 2011;72:44-52.

30. Lauber C, Nordt C, Braunschweig C, Rossler W. Do mental health professionals stigmatize their patients? Acta Psychiatr Scand Suppl 2006;113:51-9. 